\title{
Take Out Your Cell Phones - Class is Starting -- Revisited
}

\author{
Jason Bazylak, Susan McCahan, Peter Elliot Weiss, and Phil Anderson \\ University of Toronto \\ jbazylak@mie.utoronto.ca mccahan@mie.utoronto.ca weissp@ecf.utoronto.ca p.anderson@utoronto.ca
}

\begin{abstract}
Traditionally cell phones have been viewed as disruptive and an obstacle to pedagogy in the classroom. Three years ago, a survey of students led us to the conclusion that the presence of cell phones is inevitable, and rather than fight a losing battle we adopted them into our classroom pedagogy. At CEEA 2012 the authors presented the initial results of a pilot project and the preliminary results of a first year implementation. The adhoc implementation resulted in many successes in removing barriers to student instructor interaction such as lecture hall size, high peer pressure, and low student confidence. Unfortunately this adhoc implementation was also resource intensive and had limited room for expansion. In the 2012-13 academic year the course has redesigned its use of cell phones in the classroom to take advantage of a newly developed commercial classroom engagement software called Top Hat. This new implementation has allowed the authors to achieve the benefit of the adhoc system, an innovative method of asking questions in class, while also replacing the existing classroom response system. Students are now able to use Short Messaging Service (SMS) on their cell phones to both ask questions in real time and response to word, numeric or multiple choice questions posed by the instructor. Additionally the system has extensive room for growth. The logistics of the current initiative, student and instructor impressions, and future plans for the technology in our classroom will be discussed.
\end{abstract}

Keywords: text messaging, SMS, active learning, large class, educational technology

\section{INTRODUCTION}

This paper is an expansion of the original paper, Take Out Your Cell Phones - Class is Starting [1] published in the 2012 CEEA conference proceedings. The initial paragraphs in this introduction are repeated here to set the stage for a description of the implementation and impact measurement of a new classroom engagement system.

In a large first-year engineering course with approximately 1000 students seated in a single lecture hall, student - instructor engagement has always been challenging (See Figure 1).

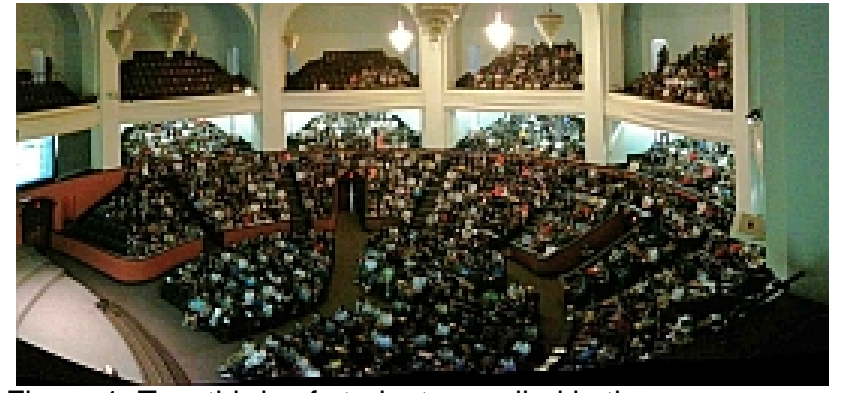

Figure 1: Two-thirds of students enrolled in the course

Large classroom active learning techniques such as Think-Pair-Share and in-classroom conceptual design challenges have all been utilized with good success, but the inability to assign grades to these activities means that a significant portion of the students do not participate.

In Fall 2007 a technological solution was attempted through the adoption of a multiple choice classroom response system, Iclickers [2]. Students interested in participating would purchase an electronic device (See Figure 2) to answer questions posted in lecture. The first year of Iclickers was unsuccessful as it was optional for students to participate. With no grades to motivate them, few bothered to purchase the device.

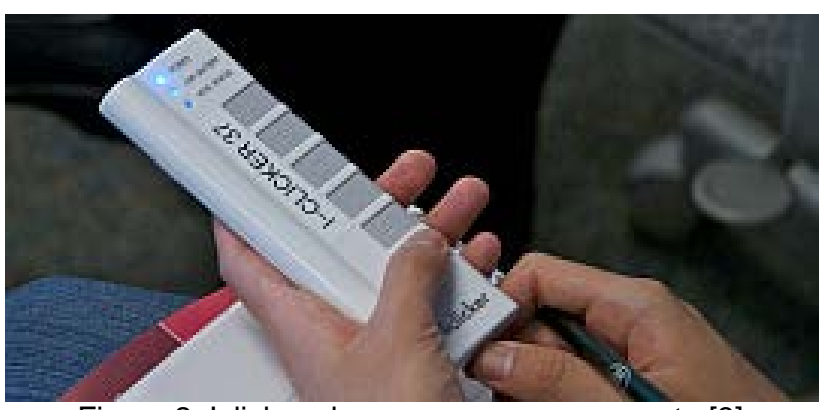

Figure 2: Iclicker classroom response remote [3]

In Fall 2008 we began allocating 3\% of the course final grade to Iclicker participation which resulted in all but the more steadfast resisters participating.

The implementation of the Iclickers was optimized over the years, taking into consideration whether to give grades only if the student gets the correct answer or 
simply to give “participation” grades. Instructors reported a positive contribution of Iclickers to the instructorinitiated classroom engagement (instructor asking questions of the students); however it did nothing for student-initiated engagement (students asking questions of the instructor). Any student with a question was left with the classic hand-in-the-air method.

Asking questions in lecture required first that the student not be intimidated by the large forum, second for the instructor to notice the single hand in a sea of faces, third for the student to project their voice in sufficient volume to be heard from a great distance, and finally for the instructor to be able to hear, understand, and then answer the question. This was time consuming, particularly when there was a back and forth dialogue between the instructor and student trying to understand the question. Many students were too intimidated to even make the attempt. Therefore though Iclickers enhanced classroom engagement, there was still room for improvement.

In Spring 2010 the issue of student-initiated questions in lecture was posed as a design problem to a student design team enrolled in the course. Their solution of using Short Message Service (SMS) as a medium for asking questions is given in an unpublished final design specification [4].

In Spring 2011 a three-month pilot was run using SMS for students to ask questions. A Teaching Assistant (TA), with the instructor's cell phone and a portable whiteboard, sat on stage with the instructor. Students were encouraged to use standard SMS to send questions to the instructor through the TA. The TA summarized and presented the questions to the instructor at appropriate times via a handheld whiteboard. Other approaches were considered, but this method had the lowest technology threshold for both the students and instructors and required minimal financial investment.

One of the first official uses of in-class texting was a creativity exercise. While standing on a table in the middle of the stage the instructor, with cell phone in hand, challenged the students to text in instruction for as many ways as possible to get him off the table. Five minutes and 300 text messages later demonstrated that use of cell phones had the potential to revitalize in classroom student - instructor interaction.

In Fall 2011 the use of SMS as a question and answer system was fully adopted in the course. The resources to implement this system were kept to a minimum. A cell phone with zero purchase price and a bare bones \$20/ month cell phone plan was all that was required. The only significant resource course cost was the time of the teaching team staff member, three hours per week over two terms.

The first run was a success and we were planning on reusing the system the next year with only minor improvements, such as a more solidified process for posting a FAQ list of questions asked in lecture.

In Summer 2012 we became aware of a commercial software-based "classroom engagement system" called Top Hat (TH) [5]. There were many features of this system, but the one we were primarily interested in was the classroom response system. We wanted to combine the currently separate student initiated SMS questions and the Iclickers into one system. After considering the criteria important to the course, detailed below, we decided to implement TH for Fall 2012.

\subsection{Students use SMS or Internet to connect}

SMS connections meant that we could continue with the existing methodology of students using their cell phones, smart or not, to send in their questions. They would not require any additional hardware.

Currently our lecture hall is not equipped to handle the number of WiFi connections that would be needed for all students to participate through internet connections. However expansion of the WiFi infrastructure is pending and this would give us an easy way to expand our functionality in the future without changing technology.

\subsection{Reply via SMS directly from the software}

Some student questions do not have lecture-level discussion value, such as "What day is the midterm on?" In the adhoc system the lecture assistant would respond privately to these questions via the cell phone. The ability to send SMS responses directly from the software means that no classroom cell phone is required.

\subsection{Two way communication}

Through our adhoc system students were able to text questions; however they required additional hardware, an Iclicker remote, to response to the graded in-lecture questions posed by the instructor. Allowing for two-way communication meant that the Iclicker system could be eliminated.

\subsection{Digital Question Database}

All questions, student and instructor initiated, are digitally stored in $\mathrm{TH}$. With ease, instructor-initiated questions could be made available to the students, along with the correct answer, as a study aid. Student-initiated questions would need to be manually inputted into the Learning Management System to be made available to the students, but it did reduce the need for transcription of questions off the cell phone screen.

\subsection{Expanded Question Types}

$\mathrm{TH}$ supports word and numeric answers in addition to multiple choice. If internet connections are used, as we hope to in the near future, the number of question types 
will expand greatly to include sorting, matching, and "click on target” [5].

\section{METHODOLOGY}

With the decision made to attempt a full implementation of $\mathrm{TH}$ in Fall of 2012 preparations began as described below.

\subsection{Initial Set up}

In Fall 2012 implementation of $\mathrm{TH}$ went live in the course. Since the system runs on TH servers and is browser accessed there was no hardware or even software installation needed. Training consisted of a two-hour inperson training session followed by several weeks of back and forth emailed questions between the teaching team and TH support as we got used to the system. Student targeted usage documentation, supplied by $\mathrm{TH}$, was embedded into our existing course documents.

Students were recommended to purchase a TH account either online directly from TH or by purchasing a voucher from the bookstore. The most common price per student was $\$ 38$ for a five year unlimited license. To compensate for the risk of utilizing a new-to-us system, students purchasing in the first term received a 50\% discount.

Students set up their own accounts, but this was relatively painless. While by no means issue-free, we found there to be fewer issues than with our previous classroom response systems. The few issues we did see resulted primarily from the use of the wrong unique identification number. The good news is that while these issues were being ironed out student data was still being collected and could be allocated to the student after the fact.

Inputting questions into $\mathrm{TH}$ was likewise relatively painless. Each instructor would write his or her own inlecture questions. Once the questions were written they could be inputted into the system from any computer in one to two minutes per question. Because we had five instructors sharing the same lecture section, keeping these questions organized was important. TH questions can be dragged and dropped around as in a typical GUI file system. This, coupled with our standardized question titles (I.E. 01-03-02 Stakeholders means Week 01, $3^{\text {rd }}$ lecture of the week, $2^{\text {nd }}$ question of the lecture on the topic of Stakeholders), allowed for the organization we needed.

Setup of the open forum for texting in questions during lecture, called discussion questions (See Figure 3), was also relatively painless. Functionally these are the same as instructor-initiated questions, except that the discussion is open for the whole lecture. Discussion questions are kept separate in the question file system and can be created ahead of time allowing us to prepare by having all the discussion questions loaded before the term started.

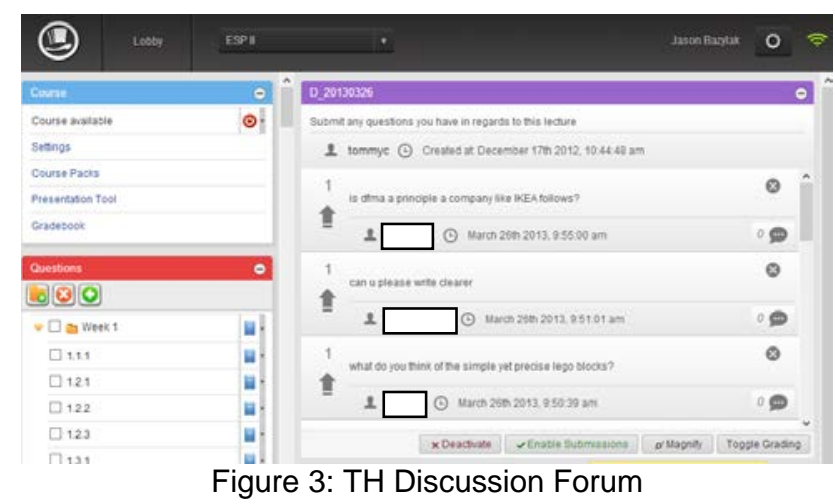

\subsection{Use in Lecture}

While possible for the instructor to run the TH system in parallel with lecturing, we chose to have a lecture assistant present at all lectures to act as a buffer between the instructor and $\mathrm{TH}$. This was a commitment of $\sim 35$ hours of time per term; however the role could have also been run by a TA. This decision was made to minimize the potential negative impacts this technology may have on the instructor's lecture, such as use of lecture time for "technology overhead." An unanticipated benefit was that for guest instructors there was a shallow learning curve for them to use the system.

Our use of $\mathrm{TH}$ to increase classroom engagement is broken down into two distinct uses. Instructor-initiated questions and Student-initiated questions. For either type of question the cell phone number used by students to interact via SMS is the same.

Instructor-initiated questions were formerly handled by the Iclicker system. These are the questions that the instructor will activate and make visible to the students when they deem it appropriate. For example after defining "Stakeholder Interest" the instructor may ask the students to identify the correct stakeholder interest from a multiple choice list. We assigned a small grade to answering these questions.

Student-initiated questions were formerly handled by the lecture assistant with a cell phone. At the start of lecture the lecture assistant would make the discussion question, "Send in questions for the Instructor?" visible to the students and notify the students of the four digit code required to send questions to the discussion. This question is visible and receiving questions for the whole lecture. There are no grades associated with student participating in this discussion.

If the question asked is of limited discussion value then the lecture assistant can answer it directly in the discussion forum, complete with sending the answer back to the student through SMS. If however the question is best answered by the Instructor then the question is 
transcribed to a handheld whiteboard. The lecture assistant continues to add questions to this whiteboard until an appropriate break in the lecturing. Typically this happens during the pause to collect student answers to an instructor-initiated question.

Questions for the instructor that are not answered in lecture are dealt with immediately after lecture. The lecture assistant copies unanswered questions from the discussion forum into a document file. This file is then emailed to the instructor to answer the questions by typing directly into the document file and returning it to the lecture assistant via email. The lecture assistant then posts these questions and answers on the Learning Management System. Finally, the lecture assistant returns to the discussion forum to send an SMS to each student whose question is now answered and posted on the course portal.

\section{RESULTS AND DISCUSSION}

Having used TH for eight months we have collected data on its usage and feedback from both instructors and students. The challenges we faced as a first time implementation were not show stoppers, but were definitely not negligible.

\subsection{Usage}

We assigned $5 \%$ of the final course grade, both fall and winter terms, to the instructor-initiated questions. The value was purposely selected to be significant so as to motivate students to participate, but not so large as to encourage cheating.

Bring Your Own Device (BYOD) initiatives commonly raise concerns that students without their "own device" are disadvantaged. With this in mind and also the regulation of the Ontario Ministry of Training, Colleges, and Universities that says that there must always be a no cost alternative for any mandatory course component, we implemented an optional paper-based system in the fall.

Before a reasonable deadline students could opt into the paper-based system if they did not have a cell phone. They were then supplied with a paper form that they could complete and hand in at the end of each lecture. Because of this paper-based system we were unable to give students marks only for the correct answers. Instead they were given marks only for participating.

For most students these participation marks and the desire to test their own knowledge were enough to motivate them to attempt to answer correctly. For a small but significant group, particularly towards the end of the fall term, it became obvious that some students were giving “dummy” answers.

In the winter term we changed the opt-out process. Before a reasonable deadline students could use an online survey to opt out of the in-lecture question system. If they opted out then the $5 \%$ of their final grade was redistributed to their exams. There was a drastic change in the opt out rate when students were presented with an option that allowed them to not attend lecture (Figure 4).

The total number of students in the fall and winter terms remained relatively constant; however the number of students using the $\mathrm{TH}$ system decreased from $97 \%$ to $61 \%$. Given this $46 \%$ difference in participants it is surprising to see only a $17 \%$ difference between the average number of users per lecture between the fall and winter terms (See Figures 5 \& 6). This indicates a trend that may not be surprising, which is that students that opt into the TH system were more likely to attend lecture.

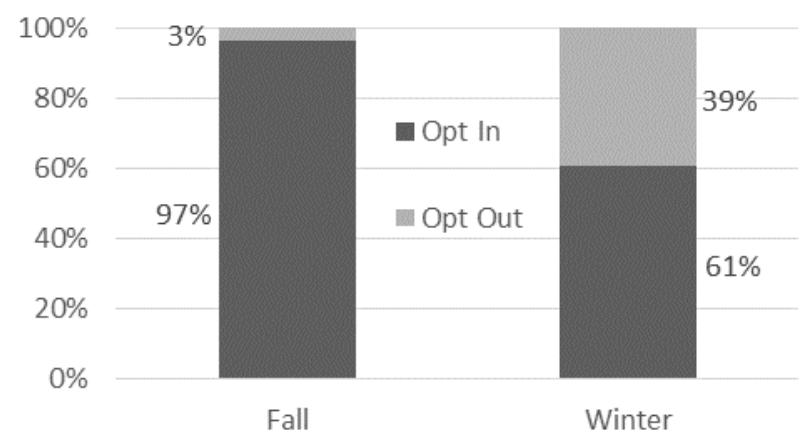

Figure 4: \% of students who opted out by term

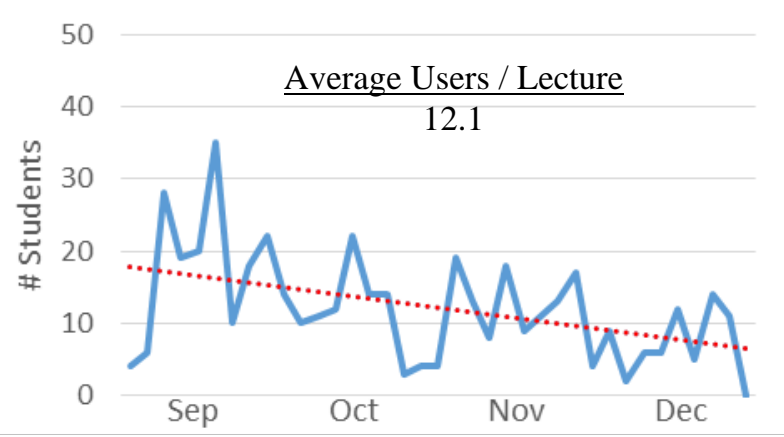

Figure 5: \# of students per lecture who text in questionsFall

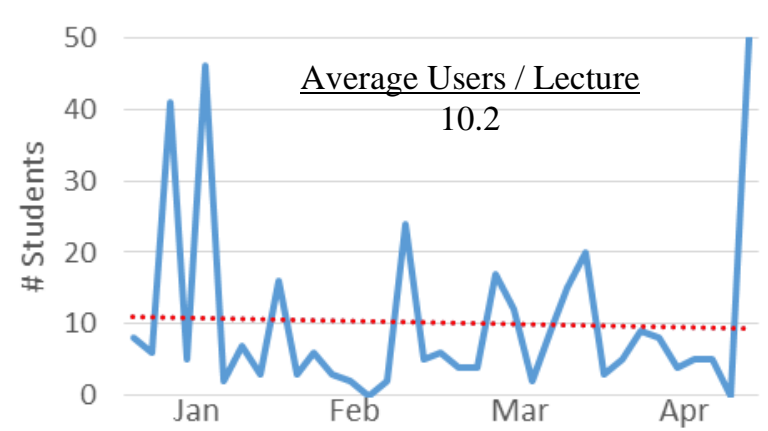

Figure 6: \# of students per lecture who text in questions Winter 


\subsection{Student Feedback}

Due to the transient nature of students, we were unable to get a student comparison between the adhoc system and the TH system. However in two end-of-term surveys, with response rates in the Fall of $20 \%$ and in the Winter of $19 \%$, students were asked to rate on a Likert scale the Usefulness / Effectiveness of the TH system. In the fall term an overwhelmingly majority of the students indicated that TH was Useful / Effective (See Figure 7).

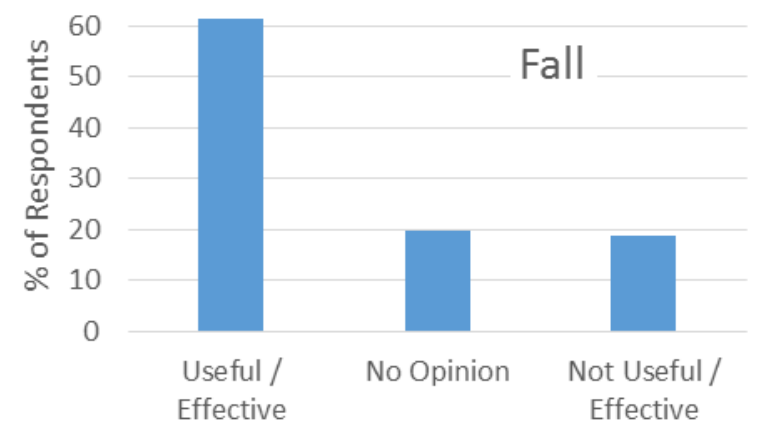

Figure 7: Student opinion of TH system - Fall

The story is entirely different in the winter term with a slight majority indicating that $\mathrm{TH}$ was Not Useful / Effective (See Figure 8). We feel that this is less likely an indication of the students' change of opinion, than it is another symptom of the change in opt-out policy. In the survey, which went out to all students in the course, students that had opted out were asked to indicate this by selecting No Opinion, but it is likely that a large number expressed their opinion negatively.

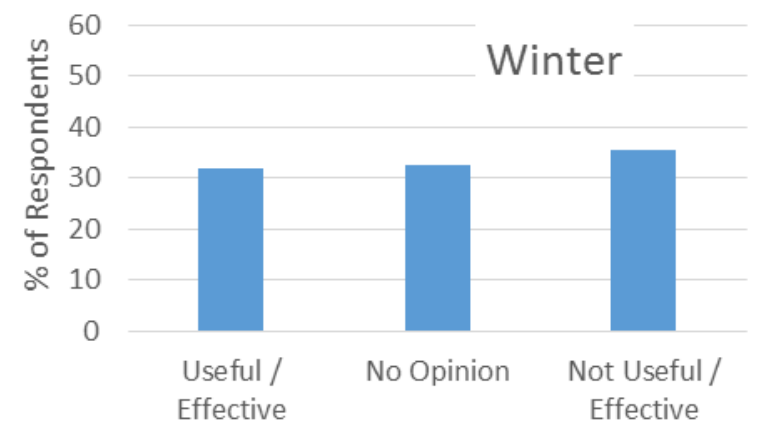

Figure 8: Student opinion of TH system - Winter

In the surveys students were not asked directly for written feedback on the $\mathrm{TH}$ system, but about $8 \%$ of respondents chose to mention it. There were a few common themes in these comments.

Do Not Want To Pay.

"I didn't like to pay for participating in the lectures."

\section{Concerned About Cheaters.}

"[N]ot ... effective in ensuring that students attend class since codes can be texted to students who aren't present."

\section{Technical Difficulties Were Frustrating.}

"I once received a response text a full 4 days after I sent in the question."

\section{Want More Difficult Questions.}

"Whenever I get a THM question wrong, I can clearly remember all of the content from the lecture related to the THM question."

\subsection{Instructor Feedback}

Through an informal process the instructors' impressions of the new TH system, including comparing it to the adhoc system used the previous year, were collected. The feedback was mixed ranging from cautiously optimistic to strongly optimistic.

"Good for instructor-initiated questions. Only OK for student-initiated questions because it takes longer to prepare than the adhoc system. This means there are less spontaneous SMS activities."

"The new system was much more robust than the previous one and the centralized database of questions with a GUI was useful."

"Honestly the added features were nice, but not anything earthshattering. However this opinion is based on our limited use of the system, limited only to SMS. Once the wireless infrastructure catches up and we can use the full features of TH it will be a game changer."

\section{CONCLUSIONS}

After its first year of implementation the TH system has met the criteria we deemed important. It has replaced our adhoc question texting system and Iclickers. The implementation was relatively pain free with the only systematic issues being the delay sometimes experienced in the cellular system and one software glitch that was created with an ill-timed start of term software upgrade.

Issues not specific to the system include:

- Devising a method of creating a no-cost alternative without sabotaging our participation rate.

- Communicating the value of participation to the students beyond simply taking attendance.

\section{FUTURE WORK}

We have experienced success with $\mathrm{TH}$, but since the market space for classroom engagement software is 
rapidly changing, we continue to explore other options. Two main contenders are:

- Course Peer: This system developed out of a senior UofT engineering student project. It has reached the commercial stage with an impressive number of features, including an interesting gamification take on course discussions [6].

- Polleverywhere.com: This system is behind on the feature set, but its advantage lies in its simplicity and its free-to-use status for small classes [7].

In the near term the wireless infrastructure will be available in lecture. When this becomes available it opens up a large number of other options for classroom engagement such as better use of graphics in questions and real time in-class backchannel discussions. We will be planning for this expansion ahead of time.

Gamification is the method of utilizing what we know motivates people to play video games to motivate them to do other things, such as learn. With the implementation of $\mathrm{TH}$ our classroom response system has been freed from the classroom. We have plans in place to use this new tool to gamify other course concepts. For instance creating a list of "small achievements" that earn students points towards larger portions of marks, and hopefully towards greater learning.

The move from classroom response systems to classroom engagement systems to systems that bring the evaluation and learning outside of the classroom is a radical change - one that we are excitedly but cautiously exploring.

\section{Acknowledgements}

This system could not have been implemented nor the data collected without the dedicated work of the course administrative staff, P. Huynh and T. Cheng. Thank you for all your support.

\section{References}

[1] J. Bazylak et al., "Class is starting - Take out your cell phones,” in Canadian Engineering Education Association 2012 $3^{\text {rd }}$ Annual Conf., Winnipeg, MB, 2012.

[2] Iclicker, [online] 2013, http://www.iclicker.com (Accessed: 07-May-2013).

[3] A. Wolf, Flickr, [online] 2013, www.flickr.com/photos/alumroot/5773972918/sizes/l/in/photost ream (Accessed: 09-May-2013).

[4] Rosemary Chiu, Hong Shen, Sung Hoon Lee, and Shruti Srinivasan. Student Feedback Mechanism in Convocation Hall at the University of Toronto. Undergraduate Design Project, Faculty of Applied Science and Engineering, University of Toronto, 2003.

[5] Top Hat, [online] 2013, www.tophat.com (Accessed: 09May-2013).

[6] Course Peer, [online] 2013, www.coursepeer.com (Accessed: 09-May-2013).

[7] Polleverywhere.com, [online] 2013, www.polleverywhere.com (Accessed: 09-May-2013). 